\title{
Physical fitness profile in elite beach handball players of different age categories
}

Luis Lemos, Vincius Oliviera, Michael Duncan, Jose Ortega, Clarice Martins, Rodrigo Campillo, Javier Sanchez, Alan Nevill, Fabio Nakamura

\begin{abstract}
The aims of this study were: 1) to compare anthropometric and fitness variables of high-level beach handball players across Under-19 (U-19), Under-21 (U-21) and senior male categories, and between male and female senior players and; 2) to test the correlations among those measures. A total of 70 high-level players (53 male of different ages) were evaluated for 5-m acceleration, 15-m sprint, horizontal jump, handgrip, specific beach handball throwing velocities, and anthropometric variables. Differences between age groups were tested using ANOVA. Independent T-Student test was used to compare fitness variables between male and female elite athletes, and Pearson partial correlation coefficients were calculated between each of the fitness variables using BMI and age as covariates. SPSS Software was used, and the level of significance was set at 95\%. The U-21 athletes better performed on horizontal jump and 6-m throw than the U-19 athletes. Senior athletes showed better performance on horizontal jump than U-19 athletes $(\mathrm{p} \leq .05)$. Positive correlation was seen for handgrip on dominant and non-dominant hands and 6-m throwing speed, and for handgrip on dominant hand and inflight velocity $(\mathrm{p} \leq .05)$. Negative correlations were observed between horizontal jump and 5-m acceleration, and $15-\mathrm{m}$ sprint $(\mathrm{p} \leq .01$ and $\mathrm{p} \leq .05$, respectively). Male athletes better performed than women in all the fitness tests. The study, for the first time, showed physical fitness comparisons between beach handball elite male athletes of different ages and between genders. These are key steps for coaches and athletes and may support future beach handball studies and practice.
\end{abstract}

KEYWORDS: Sand sports, sprinting, jumping, throwing, anthropometric. 


\section{Introduction}

Beach handball is a new Olympic sport to feature in the 2020 Olympic Games (Japan) for the first time. Beach handball is similar to court handball in the sense that it demands locomotive highintensity activities interspersed with lower intensity efforts, whilst also involving specific actions such as jumps, passes, throws and blocks [1]. There are much less body contacts (hits and pushes) during beach handball matches compared to court handball, the players in the former are required to walk/run on the unstable sand surface, which imposes higher energetic and neuromuscular demands at the same running speeds compared to firm surfaces [2,3].

These differences likely necessitate different athletic skills and physiological demands compared to traditional court handball. However, there is no research which identifies the physical fitness profiles in beach handball, despite the fact that players are expected to display high levels of physical performance in different tests, especially when completed on sand [4]. However, to the best of our knowledge, there are no studies reporting physical performance results of high-level beach handball players of both sexes and across competitive age categories. Without this information it is difficult for strength and conditioning coaches to develop effective interventions within long term athlete development models which are specific to the demands of beach handball as opposed to its more well-established court equivalent. In this aspect, court handball studies reveal that males and females differ in anthropometric characteristics and performance in maximal aerobic power, throwing, jump and sprint tests [5-7]. Apart from these expected differences, there is less agreement regarding performance indices across age categories. For instance, a study involving Norwegian female U-15, U-17, U-19 and Adult National teams revealed that the former was superior to the U17 and U-15 teams in height, mass, countermovement jump (CMJ), medicine ball throw, hand dynamometry, 10 and 30-m sprint, Yo-Yo Intermittent Recovery Test level 2 (Yo-Yo IR2), and 7-m standing ball throwing speed [8]. Fewer differences were evident between adults and U-19 players (mass, CMJ, medicine ball throw and Yo-Yo IR2). These results suggest that to reach the highest level in the adulthood, handball players must progressively improve their physical performance over the years of training.

In males, elite adults performed better than U-18 and U-16 Spanish handball players in the 10 and 20-m sprints, CMJ, muscle power tests in the squat and bench press exercises and in the jump throw and 3-step throw [9]. The U-18 presented higher performance than U-16 players concerning the load leading to $1 \mathrm{~m} \cdot \mathrm{s}^{-1}$ movement velocity during squat exercise and in the referred ball throw techniques. Hence, it appears that the specific action related to goal scoring is enhanced across all age categories investigated. This aspect also needs to be addressed in beach handball players as the final outcome of the match is determined by the ability to achieve a high throwing speed using different techniques. Specifically in beach handball, these techniques are expressed as 6-m standing, inflight 
and spin throws. The throwing velocity using these sport-specific techniques has not been addressed in the scientific literature to date.

Interestingly, in court handball players, jump throw and 3-step throw speeds have been significantly correlated with sprint, vertical jump and muscle strength performances $[8,9]$. This means that the general development of physical capacities can positively influence performance in throwing and should be constantly sought by strength and conditioning professionals and athletes. Furthermore, the sprint ability over 10 and $30-\mathrm{m}$ of handball players is positively correlated with vertical jump ability [8]. However, in beach handball the distances to be traveled while sprinting are shorter since there is up to $15-\mathrm{m}$ to run between the lines demarcating the goal areas. As a consequence, the acceleration speed on sand surface needs to be addressed in beach handball players. It is not known if jump ability (particularly the horizontal jump) is associated with acceleration speed in highly trained beach handball players.

Therefore, the aims of this study were: 1) to compare anthropometric and fitness variables of high-level beach handball players across Under-19 (U-19), Under-21 (U-21) and senior male categories, and between male and female senior players and;2) to test the correlations among those measures.

\section{Methods}

\section{Study approach and design}

This cross-sectional study examined physical, physiological, technical and tactical parameters of sand sports players (male and female). This study was conducted during the pre-game warm-ups, in the (excluded for blind review), held in (excluded for blind review), in January 2019.

Athletes from different teams were evaluated for fitness parameters, such as 5-m acceleration, 15-m sprint, horizontal jump, handgrip, and specific beach handball throwing velocities.

Tests were conducted on a beach court from 08:00 a.m. to 10:00 a.m. and from 16:00 p.m. to 18:00 p.m., according to games schedule, in a way that each player could be evaluated before his/her first game. The players were previously familiarized with the protocols and performed the respective tests in the following order: 1) handgrip strength on dominant and non-dominant hand; 2) acceleration/speed; 3) horizontal jump; 4) specific throwing velocities. Trained assessors, under the supervision of the senior researchers, conducted the tests while providing verbal encouragement to the players, especially in the all-out sprints.

Information about environmental conditions were registered during the 4-day tournament, according to the Weather Forecasting and Climate Studies Center, from (excluded information for blind review). Temperature ranged between 27.8 and $30.4{ }^{\circ} \mathrm{C}$, the air humidity between 64 and $69 \%$ and the wind velocity between 2.57 and $3.08 \mathrm{~m} / \mathrm{s}$. 
All the players were previously informed about the research aims, experimental protocol and procedures of the study and voluntarily gave their informed written consent to participate. The parents of players younger than 18 years old sign an informed consent document and both parents and athletes gave their assent before any of the tests were performed. The Helsinki Declarations' ethical aspects were followed (World Medical Association, 2013), and the evaluation methods and procedures were approved by the local Ethics Committee (excluded information for blind review).

\section{Participants}

A total of 70 players (53 male of different ages) of different ages (Elite - more than 21 yearsold [Senior]; U-21 - 19 to 20 years-old; U-19 - 17 to 18 years-old) participated in the study. The participants were involved in specific beach handball training at least twice a week (on average 90 minutes per session), and 1-2 physical/strength session(s) per week involving plyometrics, injury prevention and power training. Twenty four percent of the participants also played court handball.

\section{Anthropometric variables}

The anthropometric variables of height $(\mathrm{m})$ and body mass $(\mathrm{kg})$ were measured in each subject. Height was measured using a stadiometer (Holtain, Ltd., Pembrokeshire, UK), and body mass was measured with a bioimpedance scale (InBody 570, Biospace Co. Ltd, Seul, Korea). The BMI was calculated from body mass and body height $\left(\mathrm{kg} / \mathrm{m}^{\mathrm{m}-2}\right)$.

\section{Fitness variables}

Acceleration - 5-m and Sprint - 15-m

Participants ran two 15-m sprints on sand, separated by 5 minutes of rest. The starting position was standardized, with the lead-off foot behind the starting line, which was placed 1-m behind the first-time gate. The photocell gates were placed at the start, and at 5 and $15-\mathrm{m}$. The subjects attempted to run the $15-\mathrm{m}$ as fast as possible. The best time from the 2 attempts was recorded $(0-5 \mathrm{~m}$ : acceleration; 0-15 m: sprint). Sprint times were measured using photocells (Speed Test 6.0 standard, Cefise, São Paulo, Brazil).

\section{Horizontal Jump}

From a parallel standing position and with arms hanging loose to the side, participants were instructed to jump as distant as possible in horizontal direction and to land on both feet, with 1-min interval between three trials. The test score (best of three trials) was the distance in centimeters, measured from the starting line to the point where the most proximal heel landed on the floor. Evidence of acceptable reliability and validity of the test in athletes has been shown [10]. 


\section{Handgrip Strength}

Upper body extremities strength was measured using a handgrip dynamometer (TKK 5101 Grip D; Takei, Tokyo Japan). The participant squeezed gradually and continuously for at least two seconds, performing the test with dominant and non-dominant hand, with the elbow in full extension. The test was performed three times for each hand, with 1-min interval interspersing the consecutive trials, and the maximum score for each hand was recorded in kilograms force (kgf). The highest value registered per side was retained for analyses. This test is reliable to assess musculoskeletal fitness of upper extremities in athletes [11].

\section{Specific Beach Handball Throwing}

Specific explosive action production in beach handball was evaluated on a beach court using three different overarm throws. The players were instructed to throw a standard beach handball size (male: $450 \mathrm{~g}$; $58 \mathrm{~cm}$ circumference; female: $350 \mathrm{~g} ; 56 \mathrm{~cm}$ circumference) at maximal velocity on the upper half of the goal (over 1-m of the ground), 6-m distance of the goal, using the dominant hand. Three different specific overarm throws (6-m, spin and inflight) were performed three times per throwing type, with an interval of 1-min between consecutive trials. Firstly, athletes performed the 6$\mathrm{m}$ throwing, a standing throw equivalent to the 7-m throw in court handball. Then athletes performed the spin throw, a jumping throw with a $360^{\circ}$ body rotation, and the inflight throw, in which the athletes must grasp the ball in the air and throw it before touching their feet on the sand. These last two techniques are commonly used in beach handball.

When the speed of throws using the same technique differed more than $20 \%$, a fourth trial was performed, and the maximal throwing speed registered was kept for analysis (after eliminating the most discrepant value). The speed of each throwing was measured using a radar device (Stalker Sport; Applied Concepts, Inc., Plano, TX, USA). The radar unit was placed in $~ 2-\mathrm{m}$ behind the goal and with a height $\sim 1,5-\mathrm{m}$ from the ground.

To encourage players to perform maximally, they were immediately informed of their preceding performance. Hence, they strived to overcome the previous throws' speeds.

\section{Statistical analysis}

Descriptive procedures were performed for all variables and values are reported as mean and standard deviation (SD). The distribution of each variable was examined using the Shapiro-Wilk normality test. Homogeneity of variance was verified using Levene's test. An intraclass correlation coefficient (ICC) with a 95\% confidence interval (CI) was used to determine the between-subject reliability of tests. Within- subject variation for the tests was determined by calculating the relative 
coefficient of variation (CV). The statistical differences between age groups were tested using an ANOVA - analysis of variance, with Bonferroni's post hoc comparisons. Independent T-Student test was used to compare fitness variables between male and female elite athletes, and the percentage difference between the two groups was calculated for each fitness variable. Finally, Pearson partial correlation coefficients were calculated between each of the fitness variables using BMI and chronological age as covariates (partial correlation).

SPSS Software - version 25.0 (Macintosh) was used, and the level of significance was 95\% $(\mathrm{p}<.05)$.

\section{Results}

For the physical fitness outcomes, the within-subjects test-retest reliabilities, as measured by the $\mathrm{CV}$ and the ICCs $(95 \% \mathrm{CI})$, ranged between $0.9 \%$ (ICC=.999) for U-21 athletes' sprint in 15-m, to $6.4 \%$ (ICC.689) for 5-m acceleration of U-19 athletes. For the female ones, values ranged between $1.6 \%$ (ICC=.976) when performing sprint running to $4.4 \%$ (ICC=.983) for non-dominant handgrip, and, as shown in Table 1.

$* * * * * * * * *$ Insert Table 1 here $* * * * * * * * * * * * * * * * * *$

Mean values, SDs and outcome comparisons between age groups (males) are shown in Table 2. The U-21 athletes had a better performance on horizontal jump and 6-m throw when compared to the U-19 athletes. Senior athletes showed significantly better performance during horizontal jump than U-19 athletes $(\mathrm{p} \leq .05)$.

********** Insert Table 2 here $* * * * * * * * * * * * * * * * * *$

Results highlighted significant positive correlation between handgrip on dominant and nondominant hand and 6-m throwing speed. Positive correlations were also observed between handgrip on dominant hand and inflight velocity $(\mathrm{p} \leq .05)$. A negative correlation was observed between horizontal jump and 5-m acceleration and $15-\mathrm{m}$ sprint ( $\mathrm{p} \leq .01$ and $\mathrm{p} \leq .05$, respectively) (Table 3 ).

$* * * * * * * * *$ Insert Table 3 here $* * * * * * * * * * * * * * * * * *$

When comparing mean values between male and female athletes, male athletes performed better in all the physical fitness tests than women (Table 4). Significant differences were seen between the genders for handgrip strength on dominant and non-dominant hand. 


\section{Discussion}

This study compared physical performance characteristics of high-level beach handball male players across different age categories, and in senior players between sexes for the first time. Although there have been studies of this type for court handball players [5,12], to the best of our knowledge, this study is unique in examining beach handball. It is important to highlight that the differences in physiological and mechanical [13] aspects between beach and indoor handball are substantial. The characteristics of the environment during beach handball game and its rules create quite a very specific set of movement requirements for optimal performance, as the specific throwing techniques. As such the present study adds important information useful for coaches in preparing athletes and tailoring training programmes for this new Olympic sport.

The results of the current study showed that senior athletes better performed in the horizontal jump when comparing U-19 and U-21 players, and U-19 and senior athletes. The unbalanced sand surface presents specific challenges to the athlete in the beach-based version of handball, compared to the more established court-based version of the sport. In beach handball the ability to generate ground reaction forces is disturbed by the unstable surface and may hamper the ability to use the triple extension mechanism (i.e., extension of the ankle, knee, and hip joints) to propel the body efficiently [14]. Despite this, the current sample of highly trained players demonstrated very reproducible horizontal jump performances $(\mathrm{CV}=1.2-2.3 \%, \mathrm{ICC}=0.968-0.989)$ showing that they were sufficiently familiarized with the conditions to perform on the sand surface.

U-21 and senior players were able to jump longer than U-19 players. These differences can be possibly attributed to differences in lower body muscle power among the age groups [15], which is also observed in other team sports. For instance, a study involving futsal players performing horizontal jumps on rigid court surface demonstrated that adults (20.83 \pm 2.11 years old) performed better than younger counterparts (17.99 \pm 0.91 years old) [16]. Their performances $(240.30 \pm 11.27$ and $222.85 \pm 19.33 \mathrm{~cm})$ were greater than the ones reported in our study $(\mathrm{U}-19=205.37 \pm 21.93 \mathrm{~cm}$; $\mathrm{U}-21=226.96 \pm 28.94 \mathrm{~cm}$; senior $=223.63 \pm 17.60 \mathrm{~cm}$ ), possibly due to differences in the testing surface and the use of sports shoes in the case of futsal players.

For the specific throwing assessments, differences were seen only for the 6-m throw between the U-19 and the senior players. Three factors are determinant with regard to the efficiency of throwing: mechanics, coordination of consecutive actions of body segments, and upper and lower extremity muscle strength and power [17]. Considering that the spin and the inflight throw require a high coordination pattern, and the assessment protocol had a specific target in the goal, the maximal expression of strength-power is compromised by the difficulty of the movement sequences. Strength 
increases with age and upper-limb strength and power tests performances are related to ball velocity [17]. Therefore, when playing at an elite level, the lower complexity of the 6-m throw allows older athletes to apply a greater speed on the ball, once maximal trunk and shoulder rotation velocity and their timing have a significant influence on throwing velocity $[9,18]$. Moreover, the general greater athlete's performance in 6-m throw may be logical because of its lower coordinative requirement when comparing to the other throwing technics assessed. Therefore, it can be inferred that the assessment of the 6-m throw can be used as a proxy of strength-power abilities of beach handball players while the more complex shooting modes will involve high demands on coordination which can "hinder" the expression of more basic neuromuscular abilities [12]

It is difficult to compare current results with those from different studies that have measured throwing velocities in handball players because they differ markedly in several aspects, including methods and protocols of measurement [6]. Nonetheless, in general, the results observed for throwing velocity in the 6-m throw for the elite beach handball players are similar to the results observed in 7 $\mathrm{m}$ throw in court handball players [6].

In team handball athletes of different ages (elite, U-18 and U-16), elite players showed greater performance in almost all sprint distances (i.e. 10 and 20-m) [12]. This evidence diverges of those from this study in which no difference was seen between age categories for 5-m acceleration and 15$\mathrm{m}$ sprint. It is known that sprinting on the sand is quite different from sprinting on a hard surface [3]. The ball of the foot slips and sinks into the sand instead of directly applying ground reaction forces to stabilize the body and provide efficient forward propulsion. This instability increases the energy cost of sprinting on sand for two reasons: a) the additional mechanical work on such surface and b) a decrease in the efficiency of positive work done by the muscles and tendons [19]. Although the age groups do not differ in anthropometric variables, the seniors' tendency of having heavier body mass may explain the non-observed expected better performance for them, when comparing to the younger players. Nonetheless, seniors' higher body mass, compared to younger peers, obligates them to produce higher absolute mechanical power during sprint running to run at similar speed.

Though no difference between age categories was seen for handgrip strength, the ability to grasp the ball is essential in beach handball, considering that specific beach handball techniques, as the spin throw and the inflight naturally demand a great grasping skill. It is thus apparent that beach handball players develop this specific strength early in their prospective careers and are able to retain it toward adulthood.

When comparing team handball athletes with different training backgrounds, Gorostiaga et al. [6] suggested that elite handball players have been getting taller and heavier over the last two decades. We did not observe any difference in body size (height, body mass, and BMI) of male beach handball players of different ages. Considering beach handball is a faster game than court handball, and is 
characterized by several offensive and defensive transitions, this result might indicate that beach handball players seems to be leaner than their court peers. These differences might be explained by several reasons: a) beach handball is a non-contact sport, and greater body dimensions might not be as necessary as in court handball; b) the locomotion ability in sand surface might be impaired for those athletes with higher body mass, making it difficult for them to produce higher mechanical power during vertical jumping and sprint running, for example [6].

The present study also adds important insight into physical performance characteristics between high-level male and female senior players. As expected, we observed clear sex differences in all the evaluated variables. It is well known that physiological differences exist between the sexes, since men in general are taller and heavier, with larger muscle mass, stronger, faster and have a higher $\mathrm{VO}_{2} \max$ than women [20]. Nonetheless, although male athletes showed greater differences in handgrip strength, the differences between sexes were smaller when considering acceleration and sprint. This fact may be explained by the task nature, which demands body mass transportation [21]. So, for beach handball elite athletes, the observed results are in line with previous studies in several sports $[22,23]$.

The correlations among the fitness characteristics to determine which ones explain performance in short sand sprints and shooting techniques. Our results highlighted that horizontal jump, acceleration and speed were significantly correlated. This is not surprising since the horizontal jump distance reveals the athlete's ability to produce horizontal (+vertical) forces against the ground [24]. It is widely reported that the magnitude of horizontal forces produced during sprinting is one of the main determinants of acceleration and sprinting performances [25,26]. Hence, although the correlations were not too high $(r=-0.369$ and -0.411$)$, they highlight the necessity of developing horizontal jump ability and its underlying mechanical factors to reach high speeds on the sand surface.

The positive correlation between handgrip strength in the dominant hand and throwing velocity in 6-meter and inflight throw may be explained by the kinetic chain of the movement, in which hand is the terminal point of contact, where generated forces and torques are transferred to the implement [27]. Throwing velocity requires the ability to grip the ball in order to create control over it and increase the ball spin that leads to improvement in throwing velocity [28]. Furthermore, according to McDaniel [29], an increment in handgrip strength not only improve the skills related to grasping the object, but can also increase the amount of force generated in the throw.

To the best of the authors' knowledge, this study is the first to investigate the physical fitness characteristics of elite beach handball players of different ages, including 17 senior world champion athletes (7 males and 10 females), and U-19 and U-21 National team players. Identifying important characteristics for talent identification and selection in young athletes has proved to be a challenging 
task. So, this study may support small teams or federations to profit from structured talent detection and identification programmes.

Additionally, beach handball is a relatively new sport and although male and female (excluded for blind review) national teams are well classified in the international rankings (5 male world championship titles and 3 female world championship titles), players are not professionals. Therefore, it is only possible for them to train 3-4 times per week, once they need to divide their daily routine between training and working. This fact may compromise their overall fitness performance, when comparing to other professional team handball and/or sand surface's athletes. Nonetheless, due to a natural increase in beach handball interest, its physical demands play an important role for coaches and sports professionals, and represent an essential tool to exploit and sustain player's technical and tactical qualities throughout an entire game.

\section{Conclusion}

The current study, for the first time, presents physical fitness comparisons between beach handball elite male athletes of different ages and female ones. U-21 athletes better performed on horizontal jump and 6-m throw when compared to U-19 ones. Senior athletes better performed horizontal jump than U-19 ones. No difference between age categories was seen for handgrip strength. This study showed men performed better in all the physical fitness tests and had better body composition profile than women. A positive correlation between handgrip on dominant and nondominant hand and 6-m shooting speed, and between handgrip on dominant hand and infight's speed was seen. Negative correlation was observed between horizontal jump and 5-m acceleration and 15$\mathrm{m}$ sprint. These results are key steps for coaches and athletes and may support future beach handball studies and practice.

\section{References}

1. Pueo, B.; Jimenez-Olmedo, J.M.; Penichet-Tomas, A.; Ortega Becerra, M.; Espina Agullo, J.J. Analysis of TimeMotion and Heart Rate in Elite Male and Female Beach Handball. J Sports Sci Med 2017, 16, 450-458.

2. Zamparo, P.; Perini, R.; Orizio, C.; Sacher, M.; Ferretti, G. The energy cost of walking or running on sand. Eur J Appl Physiol Occup Physiol 1992, 65, 183-187, doi:10.1007/bf00705078.

3. Pinnington, H.C.; Dawson, B. The energy cost of running on grass compared to soft dry beach sand. J Sci Med Sport 2001, 4, 416-430.

4. Binnie, M.J.; Peeling, P.; Pinnington, H.; Landers, G.; Dawson, B. Effect of surface-specific training on 20-m sprint performance on sand and grass surfaces. J Strength Cond Res 2013, 27, 3515-3520, doi:10.1519/JSC.0b013e31828f043f.

5. Wagner, H.; Fuchs, P.; Fusco, A.; Fuchs, P.; Bell, W.J.; Duvillard, S.P. Physical Performance in Elite Male and Female Team Handball Players. Int J Sports Physiol Perform 2018, 1-24, doi:10.1123/ijspp.2018-0014.

6. Gorostiaga, E.; Granados, C.; Ibanez, J.; Izquierdo, M. Differences in physical fitness and throwing velocity among elite and amateur male handball players. Int. J. Sports Med. 2005, 26, 225-232.

7. Granados, C.; Izquierdo, M.; Ibañez, J.; Bonnabau, H.; Gorostiaga, E.M. Differences in physical fitness and throwing velocity among elite and amateur female handball players. Int J Sports Med 2007, 28, 860-867, doi:10.1055/s-2007-964989. 
8. Saavedra, J.M.; Kristjánsdóttir, H.; Einarsson, I.; Guðmundsdóttir, M.L.; Porgeirsson, S.; Stefansson, A. Anthropometric Characteristics, Physical Fitness, and Throwing Velocity in Elite women's Handball Teams. $J$ Strength Cond Res 2018, 32, 2294-2301, doi:10.1519/JSC.0000000000002412.

9. Ortega-Becerra, M.; Pareja-Blanco, F.; Jimenez-Reyes, P.; Cuadrado-Penafiel, V.; Gonzalez-Badillo, J.J. Determinant Factors of Physical Performance and Specific Throwing in Handball Players of Different Ages. $J$ Strength Cond Res 2018, 32, 1778-1786, doi:10.1519/JSC.0000000000002050.

10. Krishnan, A.; Sharma, D.; Bhatt, M.; Dixit, A.; Pradeep, P. Comparison between Standing Broad Jump test and Wingate test for assessing lower limb anaerobic power in elite sportsmen. Med J Armed Forces India 2017, 73, 140-145, doi:10.1016/j.mjafi.2016.11.003.

11. Trosclair, D.; Bellar, D.; Judge, L.W.; Smith, J.; Mazerat, N.; Brignac, A. Hand-Grip Strength as a Predictor of Muscular Strength and Endurance. The Journal of Strength \& Conditioning Research 2011, 25, S99, doi:10.1097/01.JSC.0000395736.42557.bc.

12. Ortega-Becerra, M.; Pareja-Blanco, F.; Jiménez-Reyes, P.; Cuadrado-Peñafiel, V.; González-Badillo, J.J. Determinant factors of physical performance and specific throwing in handball players of different ages. The Journal of Strength \& Conditioning Research 2018, 32, 1778-1786.

13. Binnie, M.J.; Dawson, B.; Pinnington, H.; Landers, G.; Peeling, P. Sand training: a review of current research and practical applications. J Sports Sci 2014, 32, 8-15, doi:10.1080/02640414.2013.805239.

14. Smith, R. Movement in the Sand: Training Implications for Beach Volleyball. Strength \& Conditioning Journal 2006, 28, 19-21.

15. Nikolaidis, P. Age-related differences in countermovement vertical jump in soccer players 8-31 years old: the role of fat-free mass. American Journal of Sports Science and Medicine 2014, 2, 60-64.

16. Ayarra, R.; Nakamura, F.Y.; Iturricastillo, A.; Castillo, D.; Yanci, J. Differences in Physical Performance According to the Competitive Level in Futsal Players. J Hum Kinet 2018, 64, 275-285, doi:10.1515/hukin-20170201.

17. Marques, M.C.; van den Tilaar, R.; Vescovi, J.D.; Gonzalez-Badillo, J.J. Relationship between throwing velocity, muscle power, and bar velocity during bench press in elite handball players. Int J Sports Physiol Perform 2007, 2, 414-422.

18. Wagner, H.; Pfusterschmied, J.; Von Duvillard, S.P.; Muller, E. Skill-dependent proximal-to-distal sequence in team-handball throwing. J Sports Sci 2012, 30, 21-29, doi:10.1080/02640414.2011.617773.

19. Lejeune, T.M.; Willems, P.A.; Heglund, N.C. Mechanics and energetics of human locomotion on sand. J Exp Biol 1998, 201, 2071-2080.

20. Åstrand, P.-O.; Rodahl, K.; Dahl, H.A.; Strømme, S.B. Textbook of work physiology: physiological bases of exercise; Human Kinetics: 2003.

21. Barbieri, D.; Zaccagni, L.; Babic, V.; Rakovac, M.; Misigoj-Durakovic, M.; Gualdi-Russo, E. Body composition and size in sprint athletes. J Sports Med Phys Fitness 2017, 57, 1142-1146, doi:10.23736/s0022-4707.17.069250 .

22. Cheuvront, S.N.; Carter, R.; DeRuisseau, K.C.; Moffatt, R.J. Running performance differences between men and women. Sports Medicine 2005, 35, 1017-1024.

23. Michalsik, L.B.; Aagaard, P. Physical demands in elite team handball: Comparisons between male and female players. Journal of Sports Medicine and Physical Fitness 2015, 55, 878-891.

24. Dobbs, C.W.; Gill, N.D.; Smart, D.J.; McGuigan, M.R. Relationship between vertical and horizontal jump variables and muscular performance in athletes. J Strength Cond Res 2015, 29, 661-671, doi:10.1519/JSC.0000000000000694.

25. Morin, J.B.; Bourdin, M.; Edouard, P.; Peyrot, N.; Samozino, P.; Lacour, J.R. Mechanical determinants of 100$\mathrm{m}$ sprint running performance. Eur J Appl Physiol 2012, 112, 3921-3930, doi:10.1007/s00421-012-2379-8.

26. Buchheit, M.; Samozino, P.; Glynn, J.A.; Michael, B.S.; Al Haddad, H.; Mendez-Villanueva, A.; Morin, J.B. Mechanical determinants of acceleration and maximal sprinting speed in highly trained young soccer players. $J$ Sports Sci 2014, 32, 1906-1913, doi:10.1080/02640414.2014.965191.

27. Cronin, J.; Lawton, T.; Harris, N.; Kilding, A.; McMaster, D.T. A Brief Review of Handgrip Strength and Sport Performance. J Strength Cond Res 2017, 31, 3187-3217, doi:10.1519/jsc.0000000000002149.

28. Ferragut, C.; Vila, H.; Abraldes, J.A.; Argudo, F.; Rodriguez, N.; Alcaraz, P.E. Relationship among maximal grip, throwing velocity and anthropometric parameters in elite water polo players. J Sports Med Phys Fitness 2011, 51, 26-32.

29. McDaniel, L.W.; Jackson, A.; Gaudet, L.; Tonkin, S. Methods of Upper Body Training to Increase Overhand Throwing Power. International Education Studies 2009, 2, 28-32. 
Table 1. Reliability indexes of the assessments

\begin{tabular}{lcccc}
\cline { 2 - 4 } & $\begin{array}{c}\mathrm{U}-19 \\
(\mathrm{~N}=20)\end{array}$ & $\begin{array}{c}\mathrm{U}-21 \\
(\mathrm{~N}=13)\end{array}$ & $\begin{array}{c}\text { Senior Male } \\
(\mathrm{N}=20)\end{array}$ & $\begin{array}{c}\text { Senior Female } \\
(\mathrm{N}=17)\end{array}$ \\
\hline Horizontal jump $(\mathrm{cm})$ & $1.6(.988)$ & $1.2(.994)$ & $1.0(.989)$ & $2.3(.968)$ \\
\hline Handgrip dominant $(\mathrm{kgf})$ & $3.9(.978)$ & $3.4(.979)$ & $3.3(.989)$ & $2.6(.983)$ \\
\hline Handgrip non-dominant $(\mathrm{kgf})$ & $4.7(.984)$ & $4.5(.976)$ & $2.7(.985)$ & $4.4(.983)$ \\
\hline 6-meter throw $\left({\left.\mathrm{m} . \mathrm{s}^{-1}\right)}\right.$ & $1.6(.974)$ & $2.6(.974)$ & $2.2(.976)$ & $1.7(.974)$ \\
\hline Spin throw $\left({\left.\mathrm{m} . \mathrm{s}^{-1}\right)}_{\text {Inflight throw }\left(\mathrm{m} . \mathrm{s}^{-1}\right)}^{2.4(.980)}\right.$ & $1.2(.994)$ & $2.0(.989)$ & $1.7(.982)$ \\
\hline Acceleration $-5 \mathrm{~m}(\mathrm{~s})$ & $2.8(.947)$ & $3.1(.962)$ & $2.3(.980)$ & $3.1(.962)$ \\
\hline Speed $-15 \mathrm{~m}(\mathrm{~s})$ & $6.4(.689)$ & $2.5(.885)$ & $3.5(.859)$ & $3.0(.961)$ \\
\hline
\end{tabular}

Values are expressed as coefficient of variation (intraclass correlation coefficient). 
Table 2. Descriptive values and comparisons of body composition and physical fitness outcomes between the 3 male groups.

\begin{tabular}{|c|c|c|c|c|}
\hline & $\mathrm{U}-19(\mathrm{~N}=20)$ & $\mathrm{U}-21(\mathrm{~N}=13)$ & Senior $(\mathrm{N}=20)$ & $P$ \\
\hline Age (years) & $17.56 \pm .51$ & $20.05 \pm .91^{\mathrm{a}}$ & $28.70 \pm 6.34^{b, c}$ & $.000 *$ \\
\hline Body mass $(\mathrm{kg})$ & $76.46 \pm 17.29$ & $74.09 \pm 10.28$ & $82.17 \pm 12.66$ & N.S. \\
\hline Height (m) & $1.81 \pm .83$ & $1.81 \pm .71$ & $1.80 \pm .09$ & N.S. \\
\hline BMI $\left(\mathrm{kg} / \mathrm{m}^{-2}\right)$ & $23.03 \pm 3.58$ & $22.47 \pm 2.50$ & $25.89 \pm 2.89$ & N.S. \\
\hline
\end{tabular}

PHYSICAL FITNESS OUTCOMES

\begin{tabular}{|c|c|c|c|c|c|c|c|}
\hline & & CV (ICC) & & CV (ICC) & & CV (ICC) & \\
\hline Horizontal jump $(\mathrm{cm})$ & $205.37 \pm 21.93$ & $1.6(.988)$ & $226.96 \pm 28.94^{a}$ & $1.2(.994)$ & $223.63 \pm 17.60^{b}$ & $1.0(.989)$ & $.012 *$ \\
\hline Handgrip dom (kgf) & $54.35 \pm 11.11$ & $3.9(.978)$ & $56.30 \pm 11.18$ & $3.4(.979)$ & $59.95 \pm 10.53$ & $3.3(.989)$ & N.S. \\
\hline $\begin{array}{l}\text { Handgrip non-dom } \\
\text { (kgf) }\end{array}$ & $49.30 \pm 11.26$ & $4.7(.984)$ & $50.30 \pm 7.76$ & $4.5(.976)$ & $54.70 \pm 9.70$ & $2.7(.985)$ & N.S. \\
\hline Spin throw $\left(\mathrm{m} \cdot \mathrm{s}^{-1}\right)$ & $20.02 \pm 2.03$ & $2.4(.980)$ & $21.13 \pm 2.33$ & $1.2(.994)$ & $21.29 \pm 2.55$ & $2.0(.989)$ & N.S. \\
\hline Inflight throw $\left(\mathrm{m} \cdot \mathrm{s}^{-1}\right)$ & $20.21 \pm 1,69$ & $2.8(.947)$ & $21.06 \pm 1.74$ & $3.1(.962)$ & $21.02 \pm 2.44$ & $2.3(.980)$ & N.S. \\
\hline Acceleration $-5 \mathrm{~m}(\mathrm{~s})$ & $1.05 \pm .09$ & $6.4(.689)$ & $1.05 \pm .07$ & $2.5(.885)$ & $1.07 \pm .05$ & $3.5(.859)$ & N.S. \\
\hline Sprint $-15 \mathrm{~m}(\mathrm{~s})$ & $2.58 \pm .17$ & $2.2(.932)$ & $2.38 \pm .66$ & $0.9(.999)$ & $2.59 \pm .12$ & $2.2(.962)$ & N.S. \\
\hline
\end{tabular}

Values are expressed as mean \pm standard deviation. One-way ANOVA with Bonferroni's post-hoc; CV = coefficient of variation; ICC $=$ intraclass correlation coefficient N.S. = non-significant; *significant differences between groups ( $p \leq .05) ; a=U-19 v s . U-21 ; b=U-19$ vs. Senior; $c=U-21$ vs. Senior; Handgrip dom = dominant handgrip strength; Handgrip non-dom = non-dominant handgrip strength . 
Table 3. Matrix of correlation between physical fitness variables of male athletes.

\begin{tabular}{lcccccccc}
\hline & $\begin{array}{c}\text { Horizontal } \\
\text { jump }\end{array}$ & $\begin{array}{c}\text { Handgrip } \\
\text { dom }\end{array}$ & $\begin{array}{c}\text { Handgrip } \\
\text { non-dom }\end{array}$ & $\begin{array}{c}6 \text {-meter } \\
\text { throw }\end{array}$ & $\begin{array}{c}\text { Spin } \\
\text { throw }\end{array}$ & $\begin{array}{c}\text { Inflight } \\
\text { throw }\end{array}$ & Acceleration & Sprint \\
\hline Horizontal jump & & .088 & .072 & .262 & $.357^{*}$ & .389 & $-.369^{*}$ & $-.411^{*}$ \\
\hline Handgrip dom & .088 & & $.761^{* *}$ & $.359^{*}$ & .176 & $.294^{*}$ & -.071 & -.117 \\
\hline Handgrip non-dom & -072 & .761 & & $.378^{*}$ & .241 & .259 & -.038 & .055 \\
\hline 6-m throw & .262 & $.359^{*}$ & $.378^{*}$ & & $.665^{* *}$ & $.673^{* *}$ & -.079 & -.129 \\
\hline Spin throw & $.357^{*}$ & .176 & .241 & $.665^{* *}$ & $.656^{* *}$ & -.159 & -.163 \\
\hline Inflight throw & $.389^{*}$ & $.294^{*}$ & .259 & $.673^{* *}$ & $.656^{* *}$ & & -.293 & -.094 \\
\hline Acceleration & $-.369^{* *}$ & -.071 & -.038 & -.079 & -.159 & -.293 & $.495^{* *}$ \\
\hline Sprint & $-.411^{*}$ & -.117 & .055 & -.129 & -.163 & -.094 & $.495^{* *}$ & \\
\hline & & Partial correlations adjusted for BMI and age; $* \leq 05 ; * * \leq .01$ & &
\end{tabular}


Table 4. Comparisons between genders for all measured outcomes.

\begin{tabular}{|c|c|c|c|c|}
\hline & $\begin{array}{l}\text { Senior Male } \\
\qquad(\mathrm{N}=20)\end{array}$ & $\begin{array}{l}\text { Senior Female } \\
\qquad(\mathrm{N}=17)\end{array}$ & \%difference & $\mathrm{p}$ \\
\hline Body mass (kg) & $82.17 \pm 12.66$ & $67.51 \pm 6.53$ & 19.58 & $.000 *$ \\
\hline Height (m) & $1.80 \pm .09$ & $1.67 \pm .05$ & 7.49 & $.000^{*}$ \\
\hline BMI $\left(\mathrm{kg} / \mathrm{m}^{-2}\right)$ & $25.89 \pm 2.89$ & $24.19 \pm 2.22$ & 6.78 & $.000^{*}$ \\
\hline Horizontal jump (cm) & $223.63 \pm 17.60$ & $175.50 \pm 24.38$ & 24.11 & $.000^{*}$ \\
\hline Handgrip dominant (kgf) & $59.95 \pm 10.53$ & $38.29 \pm 5.54$ & 44.09 & $.000 *$ \\
\hline Handgrip non-dominant (kgf) & $54.70 \pm 9.70$ & $36.52 \pm 5.78$ & 39.85 & $.000 *$ \\
\hline 6-meter throw $\left(\mathrm{m} \cdot \mathrm{s}^{-1}\right)$ & $22.08 \pm 2.31$ & $17,58 \pm 1,79$ & 22.69 & $.000^{* *}$ \\
\hline Spin throw $\left(\mathrm{m} \cdot \mathrm{s}^{-1}\right)$ & $21.29 \pm 2.55$ & $16.71 \pm 1.96$ & 24.10 & $.000 * *$ \\
\hline Inflight throw $\left(\mathrm{m} \cdot \mathrm{s}^{-1}\right)$ & $21.02 \pm 2.44$ & $16.50 \pm 1.76$ & 24.09 & $.000 * *$ \\
\hline Acceleration performance $-5 \mathrm{~m}(\mathrm{~s})$ & $1.07 \pm .06$ & $1.17 \pm .01$ & 8.94 & $.011 *$ \\
\hline Sprint $-15 \mathrm{~m}(\mathrm{~s})$ & $2.59 \pm .12$ & $2.89 \pm .26$ & 10.92 & $.000 * *$ \\
\hline
\end{tabular}

